\title{
The Role of Combination Chemotherapy in the Treatment of Patients with Metastatic Breast Cancer
}

\author{
Jens Huober Beat Thürlimann \\ Brustzentrum, Kantonsspital St. Gallen, Switzerland
}

\author{
Key Words \\ Breast cancer - Metastasis · Polychemotherapy
}

\section{Summary}

Metastatic breast cancer (MBC) is usually not curable, and the primary goals of treatment are thus to control disease and symptoms, maintain quality of life, and prolong life while minimizing toxicity. Chemotherapy is still an important treatment option in $\mathrm{MBC}$, and the decision whether polychemotherapy is preferable to sequential monochemotherapy is under debate. Data are quite consistent in that response rates and time to progression are significantly increased with combination chemotherapy compared to the use of a single agent in MBC patients. Data regarding overall survival with polychemotherapy are not conclusive; however, frequently this approach was associated with increased treatment toxicity and decreased quality of life. Nonetheless, in patients with symptomatic or acute, life-threatening disease, where maximum and quick tumor remission is important, polychemotherapy should be the preferred approach. Furthermore, since some of the newer combination regimens seem to increase toxicity only slightly and substantially prolong time to progression, this approach may also be an option in patients without symptomatic disease.

\section{Introduction}

Breast cancer is a global problem and in many countries the most frequent malignancy in women. Although adjuvant treatment will be given in the majority of patients, metastatic

\author{
Schlüsselwörter \\ Mammakarzinom - Metastasen · Polychemotherapie
}

\section{Zusammenfassung}

Kommt es zu einer Fernmetastasierung, ist eine Brustkrebserkrankung gewöhnlich nicht mehr heilbar. Krankheits- und Symptomkontrolle sind daher neben dem Erhalt der Lebensqualität und einer Verlängerung des Überlebens Ziele der Behandlung. Der Einsatz einer Chemotherapie ist in der metastasierten Situation immer noch ein wichtiger Teil der Behandlung. Ob jedoch eine Kombinationschemotherapie einer Monochemotherapie vorzuziehen ist, ist nach wie vor umstritten. In Bezug auf das progressionsfreie Überleben und die Ansprechraten war in den meisten Studien die Kombinationschemotherapie einer Monochemotherapie überlegen. Ein Überlebensvorteil konnte bisher jedoch nicht eindeutig durch den Einsatz einer Polychemotherapie nachgewiesen werden. Häufig waren aber mit einer Kombinationschemotherapie die $\mathrm{Ne}$ benwirkungen höher und die Lebensqualität vermindert. Dennoch ist bei Patientinnen mit symptomatischer Erkrankung oder akut lebensbedrohlicher Situation, wenn eine rasche Tumorremission im Vordergrund steht, die Kombinationschemotherapie zu bevorzugen. Da jedoch mit einigen neueren Kombinationstherapien das progressionsfreie Überleben substantiell verlängert war, mit nur wenig mehr Nebenwirkungen im Vergleich zur Monotherapie, kann dieser Therapieansatz auch für Patientinnen ohne symptomatische Erkrankung eine Therapieoption sein.

breast cancer (MBC) develops in $30-40 \%$ of all patients with breast cancer. With distant metastases present, the disease is usually not curable and remains a challenge for the treating physician. Median survival from diagnosis of metastatic disease is $2-3$ years with only a minority of $5-10 \%$ of patients

\begin{tabular}{ll}
\hline KARGER & ( 2009 S. Karger GmbH, Freiburg \\
Fax +497614520714 & Accessible online at: \\
Information@Karger.de & www.karger.com/brc \\
www.karger.com &
\end{tabular}


alive beyond 5 years [1]. The primary goals of treatment are to control disease and symptoms, and to prolong life while minimizing toxicity. Further goals are to maintain physical and social function as well as quality of life (QoL). Endocrine therapy is the treatment of first choice in patients with potential endocrine-sensitive tumors unless acute life-threatening or highly symptomatic disease has been diagnosed [2]. Furthermore, monotherapy with trastuzumab may be a reasonable alternative first-line treatment to immunochemotherapy in some patients with MBC and HER2 overexpression [3]. Unfortunately, the majority of these patients will have primary resistance or eventually develop resistance to endocrine treatment or immunotherapy. In this case, and in patients without sufficient hormone receptor or HER2 expression, chemotherapy is still the mainstay of treatment in the metastatic setting.

For a long time, a common assumption has been that combining agents will result in both superior response rates (RR) and increased disease-free or even overall survival. However, combination chemotherapy has also been associated with increased treatment complexity and toxicity and, frequently, decreased QoL. Thus, the question whether polychemotherapy is preferable to sequential monochemotherapy is still under debate [4]. This review will briefly summarize the results of trials comparing combination chemotherapy with monochemotherapy in patients with metastatic disease (table 1) and will demonstrate that in situations of MBC, combination chemotherapy is a reasonable approach in the palliative setting.

\section{Metaanalyses}

Many trials comparing polychemotherapy with monochemotherapy in $\mathrm{MBC}$ are small and thus underpowered to detect smaller potential meaningful differences in progression-free or overall survival. Two metaanalyses have been performed to address this question. In the investigation by Fossati et al. [5], a total of 189 eligible trials were identified. For the comparison of polychemotherapy versus monochemotherapy, data were available from 15 trials with 2,442 patients. The objective RR was significantly higher in patients with polychemotherapy compared to monochemotherapy (48 vs. $34 \%$, hazard ratio (HR) 1.79). Survival data were available from 12 trials involving 1,986 patients. The HR estimates favored the combination regimens with a $18 \%$ lower risk of death (HR 0.82, confidence interval (CI) 0.75-0.90). This translates into an absolute survival benefit for combination chemotherapy of $9 \%$ at 1 year and $5 \%$ at 2 years. Mucositis was more frequently observed with single agent therapy, neurotoxicity was more frequent in the combination group. In a more recent Cochrane review [6] addressing the same issue, 28 trials including 5,707 patients could be evaluated. This analysis found a significantly higher RR (odds ratio (OR) 1.28, CI
$1.15-1.42, \mathrm{p}<0.001)$, longer progression-free survival (HR 0.78 , CI $0.73-0.83, \mathrm{p}<0.001$ ), and better overall survival (HR 0.88 , CI $0.83-0.94, \mathrm{p}<0.001$ ) for patients randomized to combination chemotherapy when compared to single agent treatment. However, more toxicities like nausea, vomiting, leucopenia, and alopecia were observed with combination regimens. Can we thus conclude, due to a better overall survival seen for the combination approach, that every patient should be treated with combination chemotherapy? There are some caveats however which need to be addressed before drawing definite conclusions and transferring these data into clinical practice. Many of the trials included in these metaanalyses were of small size with poor methodology according to today's standards and, importantly, without prospectively planned crossover in the single agent arm. However, in those studies without planned crossover, the value of two agents versus a single agent was tested but not the strategy of the combination of two drugs versus the sequential use of the same two drugs. Furthermore, the majority of trials used nowadays outdated chemotherapy regimens and did not assess the impact of the various regimens on QoL. Thus, it may be more informative to look at those single trials investigating agents more recently introduced into the clinic and with study designs comparing combination chemotherapy to the sequential use of the same drugs. In this context, it is important to note that the sequential strategy has been defined in two different ways. In some trials, the sequential approach was defined as the consecutive administration of several chemotherapies following disease progression, which can be considered as the classical sequential approach. Other trials tested a sequential monotherapy in an a priori planned multicourse sequence of different chemotherapy agents as one line of treatment without disease progression and without treatment interruption.

\section{Sequential Strategy Following Disease Progression}

The most informative trial comparing combination treatment with sequential treatment within this setting was reported by Sledge et al. [7] for the Eastern Cooperative Oncology Group (ECOG). In this trial, 739 patients with MBC without prior chemotherapy in the metastatic setting were randomized to either doxorubicin (A) or paclitaxel (P) alone, or to the combination of both drugs. At the time of progression, patients were crossed over from $\mathrm{A}$ to $\mathrm{P}$ and from $\mathrm{P}$ to A. Overall response and time to treatment failure were significantly improved with the combination treatment, whereas overall survival was without significant differences between the three treatment arms (A 18.9 months, P 22.2 months, AP 22.0 months). Furthermore, there were no significant differences in the QoL scales (FACT-B) from baseline to week 16 between the treatment arms. A and $\mathrm{P}$ as single agents had equivalent activity, and the sequence of $\mathrm{A}$ and $\mathrm{P}$ was with- 
Table 1. Results of trials comparing combination chemotherapy with monochemotherapy in MBC patients

\begin{tabular}{|c|c|c|c|c|c|c|c|c|c|}
\hline Author & Regimen & Pts, $\mathrm{n}$ & Indication & $\begin{array}{l}\text { Median } \\
\text { age, } \\
\text { years }\end{array}$ & $\begin{array}{l}\mathrm{RR}, \% \\
\text { (second } \\
\text { line) }\end{array}$ & $\begin{array}{l}\text { TTP, } \\
\text { months }\end{array}$ & $\begin{array}{l}\text { OS, } \\
\text { months }\end{array}$ & $\begin{array}{l}\text { Pts with crossover } \\
\text { in monotherapy } \\
\text { arm, \% }\end{array}$ & QoL \\
\hline \multicolumn{10}{|l|}{$\begin{array}{l}\text { Sequential strategy following } \\
\text { disease progression }\end{array}$} \\
\hline \multirow[t]{3}{*}{ Sledge $2003[7]^{\mathrm{a}}$} & $\mathrm{A}+\mathrm{P}$ & 739 & 1st line & 56 & 47 & 8.2 & 22.0 & & \\
\hline & $\mathrm{A} \rightarrow \mathrm{P}$ & & & & $36(20)$ & 6.0 & 18.9 & 58 & $=$ \\
\hline & $\mathrm{P} \rightarrow \mathrm{A}$ & & & & $34(22)$ & 6.3 & 22.2 & 59 & $=$ \\
\hline \multirow[t]{3}{*}{ Soto $2006[8]^{b}$} & $\mathrm{X}+\mathrm{T}$ & 368 & 1st-2nd line & 49 & 74 & 8.5 & 28.6 & & $\mathrm{nr}$ \\
\hline & $\mathrm{X}+\mathrm{P}$ & & & & 65 & 6.5 & 33.1 & & \\
\hline & $\mathrm{X} \rightarrow \mathrm{T} / \mathrm{P}$ & & & & 46 & 6.3 & 31.5 & 64 & \\
\hline \multirow[t]{2}{*}{ Joensuu $1998[9]^{\mathfrak{c}}$} & $\mathrm{CEF} \rightarrow \mathrm{MV}$ & 303 & 1st line & 56 & $55(7)$ & 10 & 18 & & \\
\hline & $\mathrm{E} \rightarrow \mathrm{M}$ & & & & $48(16)$ & 8 & 16 & & $\uparrow$ \\
\hline \multirow[t]{2}{*}{ Beslija $2006[10]^{\mathrm{d}}$} & $\mathrm{X}+\mathrm{T}$ & 100 & 1st line & 50 & 68 & 9.3 & 22 & & $\mathrm{nr}$ \\
\hline & $\mathrm{T} \rightarrow \mathrm{X}$ & & & & 40 & 7.7 & 19 & 74 & \\
\hline \multirow[t]{2}{*}{ Thomas $2007[11]^{\mathrm{e}}$} & $\mathrm{X}+\mathrm{I}$ & 752 & 1st-4th line & 53 & 35 & 5.8 & & & \\
\hline & $\mathrm{X}$ & & & & 14 & 4.2 & $\mathrm{nr}$ & $\mathrm{nr}$ & $\uparrow$ \\
\hline \multicolumn{10}{|l|}{$\begin{array}{l}\text { Sequential strategy without } \\
\text { disease progression }\end{array}$} \\
\hline \multirow[t]{2}{*}{ Tomova $2008[12]^{\mathrm{f}}$} & $\mathrm{T}+\mathrm{G} \times 8$ & 100 & 1st-2nd line & 54 & 31 & 7.0 & 15.5 & & $\mathrm{nr}$ \\
\hline & $\mathrm{T} \times 4 \rightarrow \mathrm{G} \times 4$ & & & & 28 & 6.7 & 15.9 & & \\
\hline \multirow[t]{2}{*}{ Conte $2004[13]^{\mathrm{g}}$} & $\mathrm{E}+\mathrm{P} \times 8$ & 202 & 1st line & 58 & 58 & 11 & 20 & na & $\uparrow$ \\
\hline & $\mathrm{E} \times 4 \rightarrow \mathrm{P} \times 4$ & & & & 58 & 11 & 26 & & \\
\hline \multirow[t]{2}{*}{ Alba $2004[14]^{\mathrm{h}}$} & $\mathrm{A}+\mathrm{T} \times 6$ & 144 & 1st line & 60 & 51 & 9.2 & 21.8 & na & $\mathrm{nr}$ \\
\hline & $\mathrm{A} \times 3 \rightarrow \mathrm{T} \times 3$ & & & & 61 & 10.5 & 22.3 & & \\
\hline \multirow[t]{2}{*}{ Fountzilas $2001[15]^{\mathrm{i}}$} & $\mathrm{EP} \times 6$ & 183 & 1st line & 56 & 42 & 8.5 & 20 & na & $\mathrm{nr}$ \\
\hline & $\mathrm{E} \times 4 \rightarrow \mathrm{P} \times 4$ & & & & 55 & 10 & 21.5 & & \\
\hline \multicolumn{10}{|l|}{$\begin{array}{l}\text { Single trials with survival } \\
\text { benefit }\end{array}$} \\
\hline \multirow[t]{2}{*}{ Albain $2008[16]^{\mathrm{j}}$} & $\mathrm{P}+\mathrm{G}$ & 529 & 1st line & 53 & 41.4 & 6.14 & 18.6 & & $\uparrow$ \\
\hline & $\mathrm{P}$ & & & & 26.2 & 3.98 & 15.8 & 16 & \\
\hline \multirow[t]{2}{*}{ O‘Shaugnessy $2002[17]^{\mathrm{k}}$} & $\mathrm{T}+\mathrm{X}$ & 511 & 1st-3rd line & 52 & 42 & 6.1 & 14.5 & & $=$ \\
\hline & $\mathrm{T}$ & & & & 30 & 4.2 & 11.5 & 17 & \\
\hline
\end{tabular}

${ }^{\mathrm{a}} \mathrm{A}: 60 \mathrm{mg} / \mathrm{m}^{2} \mathrm{~d} 1 \mathrm{q} 3 \mathrm{w}, \mathrm{P}: 175 \mathrm{mg} / \mathrm{m}^{2} / 24 \mathrm{~h} \mathrm{~d} 1 \mathrm{q} 3 \mathrm{w} ; \mathrm{A}+\mathrm{P}: \mathrm{A} 50 \mathrm{mg} / \mathrm{m}^{2}, \mathrm{P} 150 \mathrm{mg} / \mathrm{m}^{2} / 24 \mathrm{~h} \mathrm{~d} 1 \mathrm{q} 3 \mathrm{w}$.

${ }^{\mathrm{b}} \mathrm{X} \rightarrow \mathrm{T} / \mathrm{P}: \mathrm{X} 1,250 \mathrm{mg} / \mathrm{m}^{2}$ bid d1-14 q3w, T $100 \mathrm{mg} / \mathrm{m}^{2} \mathrm{~d} 1 \mathrm{q} 3 \mathrm{w}, \mathrm{P} 175 \mathrm{mg} / \mathrm{m}^{2} \mathrm{~d} 1 \mathrm{q} 3 \mathrm{w} ; \mathrm{X}+\mathrm{T} / \mathrm{P}: \mathrm{X} 825 \mathrm{mg} / \mathrm{m}^{2} \mathrm{bid} \mathrm{d} 1-14, \mathrm{~T} 75 \mathrm{mg} / \mathrm{m}^{2} \mathrm{~d} 1 \mathrm{q} 3 \mathrm{w}, \mathrm{P} 175 \mathrm{mg} / \mathrm{m}^{2} \mathrm{~d} 1 \mathrm{q} 3 \mathrm{w}$. ${ }^{\mathrm{c}} \mathrm{CEF}$ : C $500 \mathrm{mg} / \mathrm{m}^{2}$, E $60 \mathrm{mg} / \mathrm{m}^{2}$, F $500 \mathrm{mg} / \mathrm{m}^{2}$ d1 q3w; MV: M 8 mg/m², V 6 mg/m² d1 q29; E: 20 mg $/ \mathrm{m}^{2}$ weekly, M: 8 mg/m² d1 q4w.

${ }^{\mathrm{d}} \mathrm{XT}: \mathrm{X} 1,250 \mathrm{mg} / \mathrm{m}^{2}$ bid d1-14, T $75 \mathrm{mg} / \mathrm{m}^{2} \mathrm{~d} 1 \mathrm{q} 3 \mathrm{w} ; \mathrm{T} \rightarrow \mathrm{X}: \mathrm{T} 100 \mathrm{mg} / \mathrm{m}^{2} \mathrm{~d} 1 \mathrm{q} 3 \mathrm{w}, \mathrm{X} 1,250 \mathrm{mg} / \mathrm{m}^{2} \mathrm{bid} \mathrm{d} 1-14 \mathrm{q} 3 \mathrm{w}$.

${ }^{\mathrm{e}} \mathrm{X}+\mathrm{I}: \mathrm{X} 1,000 \mathrm{mg} / \mathrm{m}^{2}$ bid d1-14, I $40 \mathrm{mg} / \mathrm{m}^{2} \mathrm{~d} 1 \mathrm{q} 3 \mathrm{w} ; \mathrm{X}: 1,250 \mathrm{mg} / \mathrm{m}^{2}$ bid d1-14 q3w.

${ }^{\mathrm{f}} \mathrm{T}+\mathrm{G}: \mathrm{T} 75 \mathrm{mg} / \mathrm{m}^{2} \mathrm{~d} 8, \mathrm{G} 1,000 \mathrm{mg} / \mathrm{m}^{2} \mathrm{~d} 1.8 \mathrm{q} 3 \mathrm{w} ; \mathrm{T} \rightarrow \mathrm{G}: \mathrm{T} 100 \mathrm{mg} / \mathrm{m}^{2} \mathrm{~d} 1 \mathrm{q} 3 \mathrm{w}, \mathrm{G} 1,250 \mathrm{mg} / \mathrm{m}^{2} \mathrm{~d} 1 \mathrm{q} 3 \mathrm{w}$.

${ }^{\mathrm{g}} \mathrm{E}+\mathrm{P}: \mathrm{E} 90 \mathrm{mg} / \mathrm{m}^{2}$, P $200 \mathrm{mg} / \mathrm{m}^{2} \mathrm{~d} 1 \mathrm{q} 3 \mathrm{w} ; \mathrm{E} \rightarrow \mathrm{P}: \mathrm{E} 120 \mathrm{mg} / \mathrm{m}^{2} \mathrm{~d} 1 \mathrm{q} 3 \mathrm{w}, \mathrm{P} 250 \mathrm{mg} / \mathrm{m}^{2} \mathrm{~d} 1 \mathrm{q} 3 \mathrm{w}$.

${ }^{\mathrm{h}} \mathrm{A}+\mathrm{T}:$ A $50 \mathrm{mg} / \mathrm{m}^{2}$, T $75 \mathrm{mg} / \mathrm{m}^{2} \mathrm{~d} 1 \mathrm{q} 3 \mathrm{w} ; \mathrm{A} \rightarrow \mathrm{T}: \mathrm{A} 75 \mathrm{mg} / \mathrm{m}^{2} \mathrm{~d} 1 \mathrm{q} 3 \mathrm{w}, \mathrm{T} 100 \mathrm{mg} / \mathrm{m}^{2} \mathrm{~d} 1 \mathrm{q} 3 \mathrm{w}$.

${ }^{\mathrm{i}} \mathrm{E}+\mathrm{P}: \mathrm{E} 80 \mathrm{mg} / \mathrm{m}^{2}, \mathrm{P} 175 \mathrm{mg} / \mathrm{m}^{2} \mathrm{~d} 1 \mathrm{q} 3 \mathrm{w} ; \mathrm{E} \rightarrow \mathrm{P}: \mathrm{E} 110 \mathrm{mg} / \mathrm{m}^{2} \mathrm{~d} 1 \mathrm{q} 2 \mathrm{w}, \mathrm{P} 225 \mathrm{mg} / \mathrm{m}^{2} \mathrm{~d} 1 \mathrm{q} 2 \mathrm{w}$.

${ }^{j} \mathrm{P}+\mathrm{G}: \mathrm{P} 175 \mathrm{mg} / \mathrm{m}^{2} \mathrm{~d} 1, \mathrm{G} 1,250 \mathrm{mg} / \mathrm{m}^{2} \mathrm{~d} 1.8 \mathrm{q} 3 \mathrm{w} ; \mathrm{P}: 175 \mathrm{mg} / \mathrm{m}^{2} \mathrm{~d} 1 \mathrm{q} 3 \mathrm{w}$.

${ }^{\mathrm{k}} \mathrm{T}+\mathrm{X}$ : T $75 \mathrm{mg} / \mathrm{m}^{2} \mathrm{~d} 1 \mathrm{q} 3 \mathrm{w}, \mathrm{X} 1,250 \mathrm{mg} / \mathrm{m}^{2}$ bid d1-14 q3w; T: $100 \mathrm{mg} / \mathrm{m}^{2} \mathrm{~d} 1 \mathrm{q} 3 \mathrm{w}$.

Pts = Patients; RR = response rate; TTP = time to progression; OS = overall survival; QoL = quality of life; $\mathrm{A}=$ doxorubicin; $\mathrm{P}=$ paclitaxel;

$\mathrm{X}=$ capecitabine; $\mathrm{T}=$ docetaxel $\mathrm{C}=$ cyclophosphamide; $\mathrm{E}=$ epirubicine $\mathrm{F}=5$-fluorouracil; $\mathrm{M}=$ mitomycin; $\mathrm{V}=$ vinblastine; $\mathrm{I}=$ ixabepilone;

$\mathrm{G}=; \mathrm{nr}=$ not reported; na = not applicable.

out importance as RR and time to progression (TTF) were similar for both sequences (RR: $\mathrm{P} \rightarrow \mathrm{A}: 20 \%$, TTF 4.2 months; $\mathrm{A} \rightarrow \mathrm{P}: 22 \%$, TTF 4.5 months). In a smaller trial conducted in Mexico [8], 277 evaluable patients (of 368 enrolled) with anthracycline-pretreated MBC were randomized to capecitabine followed by a taxane (electively with either docetaxel or paclitaxel) at the time of progression, or to a combination of capecitabine and a taxane. $64 \%$ of the patients treated up- 
front with capecitabine received docetaxel or paclitaxel as second-line treatment. In this study, RRs were numerically higher for the combination treatment but without statistically significant improvement of TTP and overall survival after a median follow-up of 15.5 months. In a Finnish trial [9], 303 patients with $\mathrm{MBC}$ without previous chemotherapy in the metastatic setting, and with only a minority of patients having had adjuvant chemotherapy $(20 \%)$, were randomized to epirubicine followed by mitomycin $\mathrm{C}$ at the time of progression (or when the maximum dose of epirubicin was reached), or combination chemotherapy with cyclophosphamide, epirubicine, and 5-fluorouracil (CEF) followed by the combination of mitomycin and vinblastine when progressing (or when the maximum cumulative dose of $1,000 \mathrm{mg} / \mathrm{m}^{2}$ of epirubicin was reached). RR was slightly higher with CEF compared to epirubicine (55 vs. $48 \%$ ), but no significant difference in TTP (12 vs. 10.5 months) and overall survival (18 vs. 16 months) was found between the two groups. Treatment-related toxicity was less in the single agent arms, and QoL analysis favored the patients treated with single agents. In a smaller randomized phase 2 trial [10], 100 patients received either the combination of docetaxel (T: $75 \mathrm{mg} / \mathrm{m}^{2}$ ) and capecitabine (X: 1,250 mg/m² twice daily (bid) d1-14), or the sequence of docetaxel (T: $100 \mathrm{mg} / \mathrm{m}^{2}$ ) followed by capecitabine $\left(\mathrm{X}: 1,250 \mathrm{mg} / \mathrm{m}^{2}\right.$ bid, d1-14) in the case of progression. All patients had prior anthracyclines but no chemotherapy for MBC; only $20 \%$ of the enrolled patients had hormone-responsive disease. $74 \%$ of the patients initially treated with docetaxel received capecitabine upon progression reflecting clinical reality of daily routine. The post-study treatment was similar in both arms. In this trial, not only RR (68 vs. $40 \%, \mathrm{p}=0.004$ ) and TTP (9.3 vs. 7.7 months, $p=0.001$ ) but also overall survival were in favor of the combination treatment (22.0 vs. 19 months, $\mathrm{p}=0.006 ;$ HR 0.528). However, toxicity was increased in the combination arm with more grade 3 and 4 diarrhea (12 vs. $8 \%$ ), stomatitis (16 vs. $8 \%$ ), and hand-foot syndrome (18 vs. $4 \%)$. Neutropenic fever was high in both treatment arms with 12 and $14 \%$. Dose reductions were necessary for $52 \%$ of patients on XT and $36 \%$ of patients on $\mathrm{T} \rightarrow \mathrm{X}$. There are some caveats regarding the results of this trial. The numbers in this trial are low, the RR of almost $70 \%$ is much higher than RRs usually reported in phase 3 trials, and this trial has not been fully published in a peer review journal even though the first results were reported more than 3 years ago. Thus, to draw definitive conclusions from this trial for clinical practice, these results need to be confirmed in a bigger cohort of patients. And even if the data are confirmed, the small survival benefit has to be weighed against the excessive toxicity in patients where a cure is usually not achieved. In another trial [11], 752 anthracycline-pretreated and taxane-resistant MBC patients were randomized to the combination of ixabepilone and capecitabine or to capecitabine alone. Patients were allowed to have 3 prior chemotherapy regimens, and about half the patients did in fact have 2 or 3 prior chemotherapy regimens for metastatic disease. In these heavily pretreated patients, ixabepilone plus capecitabine prolonged TTP (median 5.8 vs. 4.2 months) relative to capecitabine. RR was also significantly increased with the combination treatment (35 vs. $14 \%$ ). Grade $3 / 4$ treatment-related sensory neuropathy ( 21 vs. $0 \%$ ), fatigue ( 9 vs. $3 \%$ ), and neutropenia (68 vs. $11 \%$ ) were more frequent with the combination therapy. Overall survival was not significantly different between the treatment groups (12.9 vs. 11.1 months, $\mathrm{p}=0.1936)$. No data have been reported regarding crossover and post-study treatment. Impact of treatment on symptoms measured by FACT-Breast Symptom Index 8 revealed a statistically significant difference in favor of capecitabine. This combination may be an option in some anthracycline- and taxane-pretreated patients where the achievement of a quick remission is of utmost importance.

\section{Sequential Strategy without Disease Progression or Interruption}

In a randomized phase 3 trial [12], MBC patients pretreated with anthracyclines in the (neo)adjuvant or metastatic setting were randomized to either the combination of docetaxel and gemcitabine for 8 cycles, or to 4 cycles of docetaxel followed by 4 cycles of gemcitabine. Sample size was calculated to be 430; however, due to poor recruitment, the trial was closed prematurely after enrollment of 100 patients only. No difference in RR, TTP, or overall survival was seen. Hematologic toxicity was higher in the sequential arm. In another trial reported by Conte et al. [13], 4 cycles of epirubicine followed by 4 cycles of paclitaxel was compared to 8 cycles of the combination of these two drugs in 202 patients not previously treated with chemotherapy in the metastatic setting. $\mathrm{RR}$, median progression-free survival, and overall survival were not significantly different between the treatment arms. Grade 3/4 neutropenia and grade 2 neurotoxicity was higher in the sequential arm. In a trial conducted in Spain by GEICAM [14], 144 patients without prior chemotherapy for MBC were randomized to 3 cycles of doxorubicin followed by 3 cycles of docetaxel, or to the combination of doxorubicin and docetaxel. RR, TTP, and survival were similar between the treatment arms; however, toxicity in terms of febrile neutropenia, asthenia, and diarrhea was higher in the combination regimen. In a trial by a Greek study group [15], 183 patients with $\mathrm{MBC}$ without chemotherapy in the advanced setting were enrolled. Patients were randomly assigned to a combination of epirubicine and paclitaxel for 6 cycles at conventional doses and intervals, or to the sequence of dose-intensified and dose-dense epirubicine for 3 cycles followed immediately by 3 cycles of paclitaxel (again dose-intensified and dose-dense) with growth factor support. No difference in RR, TTP, and overall survival was seen. 


\section{Single Trials with Overall Survival Benefit}

In a phase 3 multicenter trial [16], a total of 529 patients with $\mathrm{MBC}$ were randomly assigned to the combination of gemcitabine and paclitaxel (GP) or to paclitaxel (P) alone. Prior chemotherapy in the metastatic setting was not allowed; the majority of patients had prior anthracycline-containing (neo)adjuvant therapy (96\%). Treatment was continued until disease progression, unacceptable toxicity, or patient withdrawal. RR (41.4 vs. $26.2 \%$ ), TTP (6.14 vs. 3.98 months), and overall survival (18.6 vs. 15.8 months) were all statistically significant in favor of the combination treatment. Hematologic toxicity was more commonly observed with the combination treatment (neutropenia grade $3 / 447.7$ vs. $11.5 \%$ ). Febrile neutropenia occurred in 5 and $1.2 \%$ of combination and single agent patients, respectively. Fatigue and motor neuropathy were slightly increased with the combination. Treatmentrelated discontinuation was low in both groups (GP 6.1\%, P $3.5 \%$ ). Further therapy following progression was not pre-specified, and $55 \%$ of patients received additional chemotherapy after completion of the study treatment (except for gemcitabine, the types of additional chemotherapy were very similar in the two arms). A crossover after paclitaxel monotherapy to gemcitabine was not mandatory, and only $15.6 \%$ of the patients starting with paclitaxel actually received gemcitabine. QoL was reported to be better in patients with the combination treatment. In another trial [17], 511 patients with $\mathrm{MBC}$ and anthracycline pretreatment were randomized to docetaxel $\left(\mathrm{T} 100 \mathrm{mg} / \mathrm{m}^{2}\right)$ alone or to docetaxel $\left(75 \mathrm{mg} / \mathrm{m}^{2}\right)$ in combination with capecitabine (X $1,250 \mathrm{mg} / \mathrm{m}^{2}$ bid). Similar to the previously mentioned trial [16], RR (42 vs. $30 \%$ ), TTP (6.1 vs. 4.2 months), and overall survival (14.5 vs. 11.5 months) favored the combination approach. However, grade 3 and 4 toxicities were more frequently observed with the combination treatment, particularly more diarrhea, stomatitis, and hand-foot syndrome. Dose reduction (in $51 \%$ of both drugs) was required in $65 \%$ of the patients. Treatment-related discontinuation was higher in patients treated with the combination of both drugs (26 vs. $20 \%$ ). The majority of patients received post-study chemotherapy ( $70 \%$ after TX, 63\% after T), and only $17 \%$ of the patients in the single agent group crossed over to capecitabine. QoL for global health was assessed in 454 patients and was similar between the two treatment arms.

\section{Conclusion}

Data are quite consistent with significantly increased RRs and TTP with combination chemotherapy compared to single agents in patients with MBC. Toxicity was higher with polychemotherapy although QoL was not always adversely influenced by increased toxicity. Regarding an overall survival benefit with the use of combination chemotherapy, the data are not as robust as with TTP and RR. A survival benefit is not definitively proven, since in those trials showing an overall survival benefit for the combination approach, only a minority of the cases had a crossover to the other agent in the monotherapy arm. In patients with symptomatic disease or acute life-threatening disease, where maximum response is important, polychemotherapy is preferred to monotherapy. Since some combination regimens seem to increase toxicity only slightly (e.g. paclitaxel, gemcitabine) and significantly prolong TTP, polychemotherapy may be an option for patients other than the above, characterized as high-risk patients. However, when transferring these trial data into routine practice, clinicians should be aware that the strict inclusion and exclusion criteria of clinical trials frequently result in a selected patient population, which may limit the extrapolation of study results and thus the applicability of study-tested regimens to the general population. Thus, treatment decisions should be based on the individual patient's needs and preferences and include her medical history, comorbidities, and social situation. Newer combination therapy may also involve the combination of a cytotoxic drug with a novel biologic agent (e.g. trastuzumab or bevacizumab) [18, 19]. It has been shown that these 'new' combinations are more effective in terms of RR, TTP, and, for trastuzumab, also overall survival. Comparisons of these newer combinations (e.g. chemotherapy + bevacizumab) to traditional combination chemotherapy are eagerly awaited.

\section{Conflict of Interest}

Jens Huober: Sanofi-Aventis Speaker honoraria, Advisory Board; BMS: Advisory Board; Roche: Advisory Board; Lilly: Speaker honoraria.

Beat Thürlimann has received reimbursement for Advisory Board activities from GSK and Roche, holds stocks of Novartis and Roche and received honoraria and travel grants related to educational activities from AstraZeneca, Novartis, Janssen-Cilag, BMS, Sanofi-Aventis, Phillips Group, Prime Oncology, GSK and Ely Lilly.

\section{References}

1 Rahman ZU, Frye DK, Smith TL, et al.: Results and long term follow up for 1581 patients with metastatic breast carcinoma treated with standard dose doxorubicin containing chemotherapy. Cancer 1999;85:104-111.
2 AGO Guidelines: ago-online.org.

3 Vogel CL, Cobleigh MA, Tripathy D, et al.: efficacy and safety of trastuzumab as a single agent in first-line treatment of HER2 overexpressing metastatic breast cancer. J Clin Oncol 2002;20:719-726.
4 Cardoso F, Bedard PL, Winer EP, et al.: International guidelines for management of metastatic breast cancer: combination vs. single-agent chemotherapy. J Natl Cancer Inst 2009;101:1174-1181. 
5 Fossati C, Confalonieri C, Torri V, et al. Cytotoxic and hormonal treatment for metastatic breast cancer: a systematic review of published randomized trials involving 31,510 women. J Clin Oncol 1998;16: 3439-3460.

6 Carrick S, Parker S, Thornton CE, et al.: Single agent versus combination chemotherapy for metastatic breast cancer (review). Cochrane Database Syst Rev 2009;(2):CD003372.

7 Sledge GW, Neuberg D, Bernardo P, et al.: Phase III trial of doxoxrubicin, paclitaxel and the combination of doxorubicin and paclitaxel as front-line chemotherapy for metastatic breast cancer: an intergroup trial (E1193). J Clin Oncol 2003;21:588-592.

8 Soto C, Torrecillas L; Reyes S, et al.: Capecitabine $(\mathrm{X})$ and taxanes in patients with anthracycline pretreated metastatic breast cancer: sequential vs combined therapy results from a MOSG randomized phase III trial. J Clin Oncol 2006;24:abstr 570.

$\checkmark$ Joensuu H, Holli K, Heikinnen M, et al.: Combination chemotherapy versus single agent therapy as first- and second-line treatment in metastatic breast cancer: a prospective randomized trial. J Clin Oncol 1998;16:3720-3730.
10 Beslija S, Obralic N, Basic H, et al.: Randomized trial of sequence vs. combination of capecitabine (X) and docetaxel (T): XT vs. $T$ followed by $\times$ after progression as first-line therapy for patients with metastatic breast cancer. J Clin Oncol 2006;24:abstr 571.

11 Thomas ES, Gomez HL, Li RK, et al.: Ixabepilone plus capecitabine for metastatic breast cancer progressing after anthracycline and taxane treatment. J Clin Oncol 2007;25:5210-5217.

12 Tomova A, Brodowicz T, Tzekova V, et al.: Concomitant docetaxel plus gemcitabine versus sequential docetaxel followed by gemcitabine. J Clin Oncol 2008;26:abstr 1106.

13 Conte PF, Guarneri V, Bruzzi P, et al.: Concomitant versus sequential administration of epirubicin and paclitaxel as first-line therapy in metastatic breast carcinoma. Cancer 2004;101:704-712.

14 Alba E, Martin M, Ramos M, et al.: Multicenter randomized trial comparing sequential with concomitant administration of doxorubicin and docetaxel as firstline treatment of metastatic breast cancer: a Spanish Breast Cancer Research Group (GEICAM-9903) phase 3 study. J Clin Oncol 2004;22:2587-2593.
5 Fountzilas G, Papadimitriou C, Dafni U, et al.: Dosedense sequential chemotherapy with epirubicin and paclitaxel versus the combination, as first-line chemotherapy in advanced breast cancer: a randomized study conducted by the Hellenic Cooperative Oncology Group. J Clin Oncol 2001;19:2232-2239.

6 Albain KS, Nag SM, Calderillo-Ruiz G, et al.: Gemcitabine plus paclitaxel versus paclitaxel monotherapy in patients with metastatic breast cancer and prior anthracycline treatment. J Clin Oncol 2008;26:3950-3957.

17 O'Shaugnessy J, Miles D, Vukelja S, et al.: Superior survival with capecitabine plus docetaxel combination therapy in anthracycline pretreated patients with advanced breast cancer: phase III trial results. $\mathrm{J}$ Clin Oncol 2002;20:2812-2823.

18 Miller K, Wang M, Gralow J, et al.: Paclitaxel plus bevacizumab versus paclitaxel alone for metastatic breast cancer. N Engl J Med 2007;357:2666-2676.

19 Slamon D, Leyland-Jones B, Shak S, et al.: Use of chemotherapy plus a monoclonal antibody against HER2 for metastatic breast cancer that overexpresses HER2. N Engl J Med 2001;344:783-792. 